\title{
DISTRIBUSI SPASIAL ANEMON DAN IKAN ANEMON DI PERAIRAN KELURAHAN MALALAYANG 2 MANADO ${ }^{1}$
}

\author{
Aldi Pengan², Ari B Rondonuwu ${ }^{3}$, Alex D Kambey ${ }^{3}$
}

\begin{abstract}
This study was conducted in front of coastal villages Malalayang 2. Performed data acquisition at the date of September 16 and October 6, 2011. Located at $1^{\circ} 27^{\prime} 42.2^{\prime \prime} \mathrm{N}$ and $124^{\circ} 47^{\prime} 30.9^{\prime \prime} \mathrm{E}$. The results obtained identified seven types of anemones from 35 individuals and six types of anemones from 130 individual fish at depths of $0-15$ meters. At a depth of cluster anemones, the depth of the A (0-5 meter) 6 of the 13 individuals, the depth of $B$ (5-10 meters) 4 of the 9 individuals, and the depth of $C$ (10-15 meters) 5 of the 13 individuals. While in the cluster anemones fish depth, the depth of the A (0-5 meters) 4 of the 50 individuals, the depth of B (5-10 meters) 4 of the 32 individuals, and the depth of $C$ (10-15 meter) 6 of the 48 individual. In each type of anemones fish most of anemones occupies more than one type.
\end{abstract}

Keywords : anemones, anemones fish, depth

\section{ABSTRAK}

Penelitian ini dilakukan di depan perairan pantai Kelurahan Malalayang 2. Pengambilan data dilakukan pada tanggal 16 september dan 6 oktober 2011. Terletak pada $1^{\circ} 27^{\prime} 42.2^{\prime \prime}$ LU dan $124^{\circ} 47^{\prime} 30.9^{\prime \prime}$ BT. Hasil penelitian diperoleh 7 jenis anemon yang teridentifikasi dari 35 individu dan 6 jenis ikan anemon dari 130 individu pada kedalaman 0-15 meter. Pada kelompok kedalaman anemon, kelompok kedalaman A (0-5 meter) 6 jenis dari 13 individu, kedalaman B (5-10 meter) 4 jenis dari 9 individu, dan kedalaman $C$ (10-15 meter) 5 jenis dari 13 individu. Sedangkan pada kelompok kedalaman Ikan anemon, kelompok kedalaman A (0-5 meter) 4 jenis dari 50 individu, kedalaman B (5-10 meter) 4 jenis dari 32 individu, dan kedalaman $C$ (10-15 meter) 6 jenis dari 48 individu. Pada setiap jenis ikan anemon sebagian besar menempati anemon lebih dari satu jenis.

Kata kunci : anemon, ikan anemon, kedalaman

Bagian dari skripsi

Mahasiswa Program Studi Manajemen Sumberdaya Perairan FPIK-UNSRAT

${ }^{3}$ Staf pengajar Fakultas Perikanan dan Ilmu Kelautan Universitas Sam Ratulangi

\section{PENDAHULUAN}

Indonesia merupakan Negara yang memiliki daerah laut lebih luas dari pada daratan. Negara ini termasuk pada daerah tropis yang memiliki kekayaan laut sangat beragam. Salah satu kekayaan laut yang dimiliki oleh bangsa Indonesia adalah daerah terumbu karang. Terumbu karang merupakan keu- 
nikan diantara asosiasi atau komunitas lautan yang seluruhnya dibentuk oleh kegiatan biologis (Nybakken, 1988). Sebagai suatu habitat, terumbu karang merupakan ka-wasan yang kompleks, dimana banyak dihuni oleh berbagai biota seperti coelenterata (jenis-jenis karang batu, karang lunak dan anemon), krustasea (udang-udangan dan kepiting), echinodermata (jenis-jenis lili laut, bulu babi, ketimun laut), moluska, alga, sponges, dan berbagai jenis ikan (termasuk ikan anemon).

Teluk Manado khususnya perairan terumbu karang di depan Kelurahan Malalayang 2 merupakan salah satu daerah parawisata yang ada di Manado. Daerah ini merupakan pantai terdekat yang menjadi tempat wisata pantai dan juga sebagai salah satu tempat wisata bahari di Manado. Terumbu karang yang ada menjadikan daerah ini salah satu tempat penyelaman yang ada di Teluk Manado. Di wilayah terumbu karang ini, berasosiasi berbagai biota termasuk ikan karang baik bernilai ekonomis penting yang dapat dikonsumsi dan ikan karang yang memiliki nilai estetika. Salah satu komunitas yang berasosiasi dengan terumbu karang yaitu anemon dan ikan anemon.

Ikan anemon merupakan jenis ikan yang suka menetap. Ykan ini termasuk dalam family Pomacentridae merupakan salah satu kelompok ikan karang yang besar jumlahnya, mendiami perairan laut tropis yang umumnya tidak begitu dalam (Suharti, 1990). Ikan ini memiliki warna-warna yang cerah dan beragam ditambah dengan anemon laut yang juga memiliki warna pada setiap tentakelnya. Warna yang cerah dan beragam di miliki oleh anemon dan ikan anemon merupakan suatu keunikan pada kedua jenis hewan ini. Keunikan tersendiri dari ikan anemon yaitu apabila dalam satu koloni tidak terdapat betina, maka salah satu ikan jantan dapat merubah kelaminnya menjadi ikan betina. Jenis ikan ini selalu dijumpai hidup bersama dengan anemon laut. Semua ikan anemon hidup bersimbiosis mutualistik dengan anemon tertentu
(Allen dan Stenee, 2002). Dalam simbiosis ini, ikan mendapat proteksi dan memakan mate-rial nonmetabolik yang dikeluarkan oleh anemon. Disisi lain, anemon 'dibersih-kan' dan dilindungi dari predator oleh ikan simbionnya (Randall dan Fautin, 2002).

\section{METODE}

Penelitian ini dilakukan di depan perairan pantai Kelurahan Malalayang 2. Pengambilan data dilakukan pada tanggal 16 September dan 6 Oḱtober 2011 , pada posisi $1^{\circ} 27^{\prime} 42.2^{\prime \prime}$ 'LU dan $124^{\circ} 47^{\prime}$ 30.9" BT. Bahan dan alat yang digunakan yaitu alat SCUBA, kamera bawah air, pensil, white sheet, GPS, buku tulis, dan gambar slide tiap jenis anemon dan ikan anemon sebagai panduan identifikasi. Kegiatan pengambilan data diawali dengan melakukan survey pendahuluan. Penting dilakukan survey pendahuluan untuk dapat mengetahui dan mengenal jenis-jenis ikan anemon dan anemon yang berada di daerah penelitian dan juga bentuk dasar perairan, untuk meminimalisir kesalahan yang mungkin akan terjadi di lapangan pada saat pengambilan data.

Pada saat penelitian menggunakan metode survey jelajah sistimatis pada kelompok kedalaman, yaitu : kedalaman A (0-5 meter), B (5-10 meter), dan $C$ (10-15 meter). Pada saat pengambilan data awal dilakukan penyisiran dari kelompok $\mathrm{C}$, kemudian $\mathrm{B}$, dan terakhir A.

Kegiatan pengambilan data, setiap individu (anemon dan ikan anemon) diambil gambar dan juga khusus anemon akan diambil titik koordinat. Untuk menentukan titik koordinat setiap individu anemon dengan menggunakan GPS, dimana penyelam memberi tanda kepada 1 orang (yang memegang GPS) yang berada di permukaan laut setiap menemukan indivudu anemon.

Untuk mengidentifikasi anemon dan ikan anemon adalah dengan metode sensus visual yaitu dengan melihat karakter-karakter morfologi eksternal 
seperti bentuk-bentuk tentakel pada anemon dan pola warna pada ikan anemon. Juga dibantu dengan menggunakan buku identifikasi (Fautin dan
Allen, 1992; Allen dan Stenee, 2002; Myers. 1991; Saanin, 1984; Colin dan Arneson, 1995).

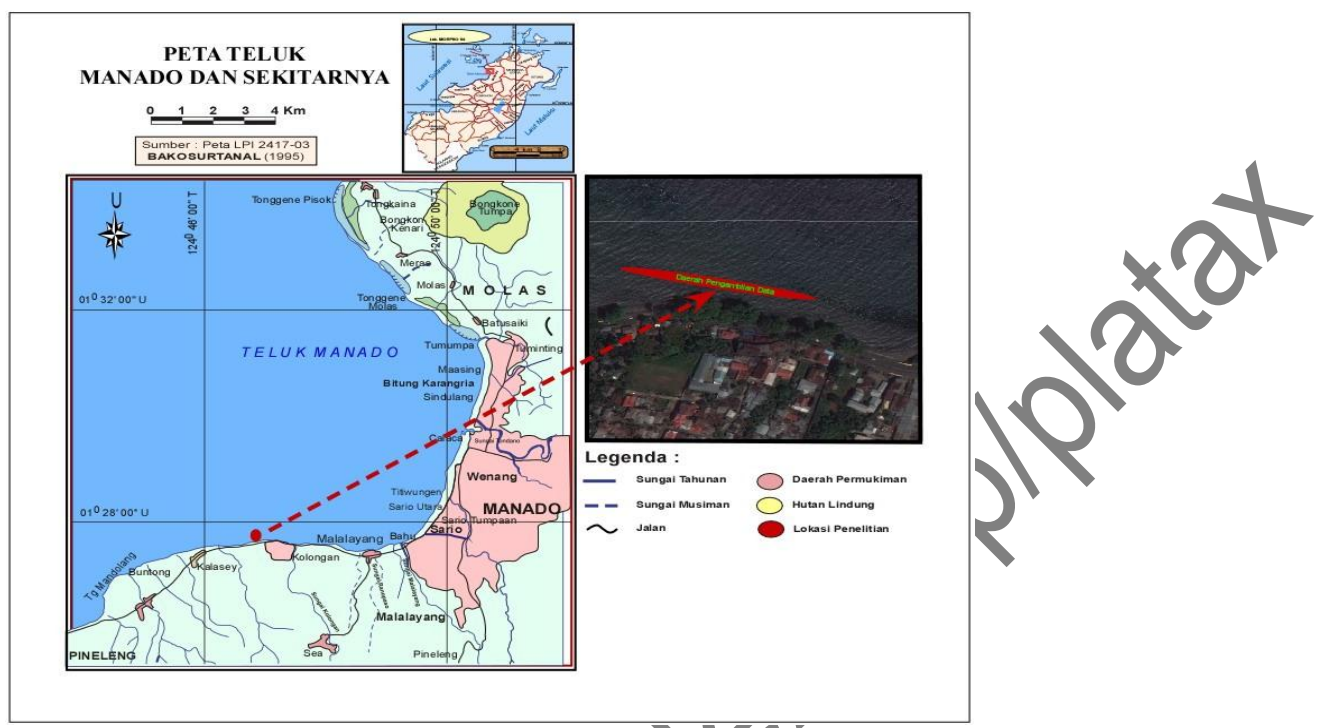

Gambar 1. Lokasi Penelitian Perairan depan Kelurahan Malalayang 2 Manado.

HASIL DAN PEMBAHASAN

Hasil pengambilan data di perairan pantai depan Kelurahan Malalayang 2 ditemukan 7 fenis anemon dan jumlah individu anemon ditemukan 35 individu. Pada tiap kelompok kedalaman berva-risai jenis dan jumlah individu anemon maupun ikan anemon. Kelompok keda-laman A (0-5 meter) didapatkan 13 indi-vidu dari 6 jenis anemon. Kelompok kedalaman B (5-10 meter) didapatkan 9 individu dari 4 jenis anemon, dan kelom-pok kedalaman $C$ (10-15 meter) didapatkan 13 individu dari 5 jenis anemon.

Rada tabel 1 dapat dilihat bahwa di kedalaman 13 meter jenis anemon Heteractis magnifica merupakan jenis yang memiliki individu paling banyak. Ada 3 kedalaman yang hanya terdapat 1 jenis anemon saja yaitu pada kedalaman 1, 6, dan 9 meter. Penelitian yang dilakukan oleh Walansendow (1997) di pulau Bunaken bagian Selatan mene-mukan 5 jenis anemon yaitu Entacmea quadricolor, Heteractis crispa, H. magnificaa, Stichodactyla haddoni, S. mertansii dari 231 individu (kedalaman 0-10 meter). Jenis yang paling banyak ditemukan dan memiliki kepadatan relatif paling tinggi adalah Heteractis crispa.

Untuk ikan anemon didapatkan 6 jenis dari 130 individu (Tabel 2). Menurut Allen (1991) terdapat 9 jenis ikan anemon yang ditemukan di Indonesia yaitu Amphiprion akallopsis, A. clarkii, A. ephippium, A. frenatus, $A$. melanopus, $A$. ocellaris, $A$. perideraion, $A$. polymnus, $A$. sebae, dan $A$. sandaracinos. Sedangkan oleh Kuiter dan Tonozuka (2001) menambahkan 1 jenis ikan anemon yang terdapat di Indonesia yaitu Amphiprion percula.

Pada pembagian kelompok kedalaman ikan anemon sangat beragam. Kelompok kedalaman A didapatkan 4 jenis ikan anemon dan 50 individu. Di kelompok kedalaman A didapatkan 2 jenis ikan anemon pada 1 jenis anemon. Kelompok kedalaman B didapatkan 4 jenis ikan anemon dari 32 individu, sedangkan pada kelompok kedalaman $\mathrm{C}$ didapatkan 6 jenis ikan anemon dari 48 individu. Pada kedalaman 
C juga di dapatkan 2 jenis ikan anemon yang berbeda tetapi menempati 1 jenis anemon yang sama yaitu jenis ikan anemon Amphiprion clarkii dan $A$. perideraion menempati anemon jenis Heteractis crispa.

Suyarso dan Agus (2008) pada penelitiannya di daerah Wakatobi menemukan 7 jenis ikan anemon pada kedalaman 5-6 meter. 4 jenis ikan anemon yang diantaranya ditemukan di perairan pantai Kelurahan Malalayang 2 yaitu Amphiprion ocellaris, $A$. sandaracinos, $A$. perideraion, dan $A$. clarkii. Sedangkan pada penelitian yang dilakukan oleh Giyanto et al. (2006) di Raja Ampat menemukan 3 jenis ikan anemon (Amphiprion akindynos, $A$. ocellaris, dan $A$. clarkii) yang diantaranya ditemukan di lokasi penelitian ini.

Jenis ikan anemon yang ditemukan di Raja Ampat yaitu Amphiprion ocellaris dan Amphiprion clarkii pada kedalaman 3-5 meter. Pada penelitian yang dilakukan oleh Lalamentik et al. (2010) di Pulau Putus-Putus dan Teluk Buyat dari 4 stasiun 2 kedalaman 3 dan 10 meter menemukan 4 jenis ikan anemon (Amphiprion clarkii, peridarion, A. akindynos dan Premnas biaculeatus). Untuk penelitian ini ditemukan Amphiprion clarkii, $A$. peridarion, dan Premnas biaculeatus.

\section{KESIMPULAN}

Ditemukan 7 jenis anemon dari 3 genera (Entacmeâ dan Macrodactyla, Heteractis, dan Stichodactyla) dengan total 35 individu. Heteractis magnifica merupakan jenis anemon yang memiliki kepadatan relatif paling tinggi yaitu 44,44\% pada kedalaman 0-15 meter. Ditemukan 6 jenis ikan anemon dari 2 genera (Amphiprion dan Premnas) dengan 130 individu. Amphiprion polymnus merupakan jenis ikan anemon yang memiliki kepadatan relatif paling tinggi yaitu $60 \%$ pada kedalaman 0-15 meter. Pada kelompok kedalaman A didapatkan 6 jenis anemon dari 13 individu, kedalaman B (5-10 meter) didapatkan 4 jenis anemon dari 9 individu, dan kedalaman $\mathrm{C}$ didapatkan 5 jenis anemon dari 13 individu. Pada kelompok kedalaman A didapatkan 4 jenis ikan anemon dari 50 individu, kedalaman B didapatkan 4 jenis anemon dari 32 individu, dan kedalaman $\mathrm{C}$ didapatkan 6 jenis anemon dari 48 individu. Umumnya, setiap jenis ikan anemon menempat lebih dari 1 jenis anemon.

\section{DAFTAR PUSTAKÀ}

Allen G.R dan R. Stenee 2002. IndoPacific Coral Reef Field Guide. Tropical Reef Research Publ. Singapore. 378p

Colin L.P dan C. Arneson. 1995. Tropical Pácific Invertebrates. A Field Guide to the Marine Invertebrates Occuring Tropical Pacific Coral Reef, Seagress Beds and Mangrove. Beverly Hills, California 90210. USA. $290 \mathrm{Hal}$.

Fautin D.G dan G.R. Allen. 1992. Field Guide to Anemon fishes and Their Host Sea Anemon. Western Austalian Museum, Francis Street Perth.

Giyanto, S.R. Suharti, W.F. Leatemia, A. Budianto, A. Salatalohi, R. Alik, Y. Hehuat, A.D. Razak, Y. Arafat, A. Latif 2006. Studi baseline ekologi Kabupaten Raja Ampat. Coral Reef Information and Training Centre (CRITC)-LIPI. Jakarta. 35 Hal.

Kuiter R.H. dan T. Tonuzuka. 2001. Pichtoral guide to : Indonesian reef fishes. Zoonetics publisher. Seaford. Australia.

Lalamentik L.T.X, A.B. Rondonuwu, U.N.W.J. Rembet. 2010. Kondisi terumbu karang pulau putus-putus Kecamatan Ratatotok Kabupaten Minahasa Tenggara. Coral Reef Information and Training Centre 4. Fakultas Perikanan dan IImu Kelautan. Manado. 46 Hal. 
Myers R.F. 1991. Micronesian Reef Fishes. A Guide to the Identification of Tropical Central and Wester Pacific. $2^{\text {nd }}$ Edition. A Cora; Graphics Production. 298 hal.

Nybakken J. 1988. Biologi Laut; suatu pendekatan ekologis. Penerbit Gramedia-Jakarta. 459 hal.

Randall, J. E dan D.G. Fautin. 2002. Fishes other than anemonfishes that associate with sea anemons. Coral Reefs, 21:188-190

Saanin H. 1984. Taksonomi dan kunci identifikasi ikan. Binacipta. Bogor. Hal 399-401.

Suharti S.R. 1990. Mengenal Kehidupan Kelompok Anemon
(Pomacentridae). Balai Penelitian dan Pengem-bangan Biologi Laut, Pusat Penelitian dan Pengembangan Oseanologi-LIPI. Jakarta. Osean, Volume XV, Nomor 4:135145.

Suyarso dan B. Agus, 2008. Baselin Terumbu Karang Daerah Perlindungan Laut Wakatobi. LIPI. Jakarta. 60 hal.

Walansendow. E. R, 1997. Keberadaan Anemon Laut dan Ikan Anemon (Amphirionninae) di Perairan Pulau Bunaken bagian Selatan. Fakultas Perikanan dan IImu kelautan. UNSRAT. Manado $46 \mathrm{Hal}$.

Tabel 1. Kelimpahan anemon padatiap kedalaman

\begin{tabular}{|c|c|c|c|c|}
\hline \multirow{2}{*}{ No } & \multirow{2}{*}{$\begin{array}{l}\text { Kedalaman } \\
\text { (meter) }\end{array}$} & \multicolumn{2}{|c|}{ Anemôn } & \multirow{2}{*}{ Substrat } \\
\hline & & Jenis & Individu & \\
\hline 1 & 1 & Stichodactyla mertensii & 2 & Karang \\
\hline 2 & 3 & $\begin{array}{l}\text { - Macrodactyla doreensis } \\
\text { - Stichodactyla haddoni } \\
\text { - Heteractis magnifica } \\
\text { - Stichodactyla gigantea }\end{array}$ & $\begin{array}{l}2 \\
1 \\
1 \\
1\end{array}$ & Pasir dan karang \\
\hline 3 & 4 & $\begin{array}{l}\text { - Macrodactyla doreensis } \\
\text { - Stichodactyla haddoni } \\
\text { Heteractis magnifica }\end{array}$ & $\begin{array}{l}1 \\
1 \\
2\end{array}$ & Pasir dan karang \\
\hline 4 & 5 & $\begin{array}{l}\text { Heteractis magnifica } \\
\text { Heteractis crispa }\end{array}$ & $\begin{array}{l}1 \\
1\end{array}$ & Pasir dan karang \\
\hline 5 & & Stichodactyla haddoni & 2 & Pasir \\
\hline 6 & & $\begin{array}{l}\text { - Stichodactyla haddoni } \\
\text { - Heteractis magnifica }\end{array}$ & $\begin{array}{l}1 \\
1 \\
\end{array}$ & Pasir dan karang \\
\hline & & Heteractis magnifica & 2 & Karang \\
\hline & 10 & $\begin{array}{l}\text { - Heteractis crispa } \\
\text { - Stichodactyla gigantea } \\
\text { - Heteractis magnifica }\end{array}$ & $\begin{array}{l}1 \\
1 \\
1\end{array}$ & Karang \\
\hline 9 & 11 & $\begin{array}{l}\text { - Stichodactyla haddoni } \\
\text { - Heteractis crispa } \\
\text { - Heteractis magnifica } \\
\text { - Heteractis aurora }\end{array}$ & $\begin{array}{l}1 \\
1 \\
1 \\
1\end{array}$ & Pasir dan karang \\
\hline 10 & 12 & $\begin{array}{l}\text { - Stichodactyla haddoni } \\
\text { - Heteractis crispa } \\
\text { - Heteractis magnifica }\end{array}$ & $\begin{array}{l}1 \\
1 \\
1\end{array}$ & Pasir dan karang \\
\hline 11 & 13 & $\begin{array}{l}\text { - Stichodactyla haddoni } \\
\text { - Heteractis magnifica }\end{array}$ & $\begin{array}{l}1 \\
3\end{array}$ & Karang \\
\hline 12 & 14 & $\begin{array}{l}\text { - Stichodactyla haddoni } \\
\text { - Macrodactyla doreensis }\end{array}$ & $\begin{array}{l}1 \\
1\end{array}$ & Pasir dan karang \\
\hline
\end{tabular}


Tabel 2. Kelimpahan ikan anemon pada tiap kedalaman

\begin{tabular}{|c|c|c|c|c|}
\hline \multirow{2}{*}{ No } & \multirow{2}{*}{$\begin{array}{l}\text { Kedalaman } \\
\text { (meter) }\end{array}$} & \multicolumn{2}{|c|}{ Ikan Anemon } & \multirow{2}{*}{ Substrat } \\
\hline & & Jenis & Individu & \\
\hline 1 & 1 & $\begin{array}{l}\text { - Amphiprion polymnus } \\
\text { - A. sandaracinos }\end{array}$ & $\begin{array}{l}7 \\
6\end{array}$ & Karang \\
\hline 2 & 3 & $\begin{array}{l}\text { - A. polymnus } \\
\text { - A. Sandaracinos } \\
\text { - A. perideraion }\end{array}$ & $\begin{array}{l}7 \\
3 \\
2\end{array}$ & Pasir dan karang \\
\hline 3 & 4 & $\begin{array}{l}\text { - A. polymnus } \\
\text { - A. perideraion } \\
\text { - A. ocellaris }\end{array}$ & $\begin{array}{l}14 \\
2 \\
3\end{array}$ & \\
\hline 4 & 5 & $\begin{array}{l}\text { - A. perideraion } \\
\text { - A. ocellaris }\end{array}$ & $\begin{array}{l}3 \\
3\end{array}$ & \\
\hline 5 & 6 & A. polymnus & 7 & Pasir \\
\hline 6 & 7 & $\begin{array}{l}\text { - A. polymnus } \\
\text { - A. perideraion }\end{array}$ & $\begin{array}{l}5 \\
2\end{array}$ & \\
\hline 7 & 9 & A. ocellaris & 7 & \\
\hline 8 & 10 & $\begin{array}{l}\text { - A. sandaracinos } \\
\text { - A. perideraion } \\
\text { - A. ocellaris }\end{array}$ & & Karang \\
\hline 9 & 11 & $\begin{array}{l}\text { - A. sandaracinos } \\
\text { - A. perideraion } \\
\text { - A. ocellaris } \\
\text { - A. clarkii }\end{array}$ & $\begin{array}{l}2 \\
3 \\
4\end{array}$ & Pasir dan karang \\
\hline 10 & 12 & $\begin{array}{l}\text { - A. polymnus } \\
\text { - A. perideraion }\end{array}$ & $\begin{array}{c}11 \\
5\end{array}$ & Pasir dan karang \\
\hline 11 & 13 & $\begin{array}{l}\text { - A. polymnus } \\
\text { - A. perideraion } \\
\text { - A. ocellaris }\end{array}$ & $\begin{array}{l}2 \\
3 \\
6\end{array}$ & Karang \\
\hline 12 & 14 & $\begin{array}{l}\text { - A. polymnus } \\
\text { - Premnas biaculeatus }\end{array}$ & $\begin{array}{l}6 \\
3\end{array}$ & Pasir dan karang \\
\hline
\end{tabular}

